\title{
Avaliação da Soroprevalência dos Virus Herpes Simples Tipos 1 e 2 em Parturientes
}

\author{
Seroprevalence Evaluation of Herpes Simplex Virus 1 and 2 Among Pregnant Women
}

Marina Carvalho Paschoini, Geraldo Duarte, Sérgio Pereira da Cunha,

Benedito Antônio Lopes da Fonseca

\section{RESUM0}

Objetivos: avaliar a soroprevalência da infecção causada pelo HSV-2 entre as parturientes do Hospital das Clinicas da Faculdade de Medicina de Ribeirão Preto (HCFMRP-USP) e padronizar técnicas laboratoriais para atender a este propósito.

Métodos: foram avaliadas 1.500 amostras de sangue de parturientes atendidas no Centro Obstétrico do Departamento de Ginecologia e Obstetricia do HCFMRP-USP, entre $1^{\circ}$ de janeiro e 31 de outubro de 1996. Para determinar a real prevalência da infecção por HSV-2 foi padronizada a técnica de ELISA, verificando-se que esta não apresentava especificidade suficiente para discriminar os dois tipos virais (75\%), delineando a necessidade de utilizarse técnica de maior poder discriminatório. A técnica padronizada para esta finalidade foi o Western blot, capaz de detectar a proteina viral especifica do HSV-2.

Resultados: a soroprevalência para infecção herpética, pelos dois tipos virais (HSV-1 e HSV2), foi de 94,5\%, utilizando a técnica de ELISA. Com o emprego da técnica de Western blot, encontrou-se a soroprevalência de 31,9\% pelo HSV-2 na população avaliada, quer sintomática ou assintomática.

Conclusão: verifica-se elevada prevalência do estado de portadora da infecção pelos HSV, evidenciada pelo alto indice de positividade para os anticorpos contra estes virus. O teste ELISA não mostrou especificidade suficiente para discriminar os anticorpos anti-HSV-2 dos anti-HSV-1.

PALAVRAS-CHAVE: Herpes virus simples. Infecção na gravidez. Malformações fetais.

\section{Introdução}

Entre as infecções virais com efeito deletério potencial sobre o feto, destacam-se aquelas causadas pelos virus da familia Herpesviridae. Incluem-se nesta familia os virus herpes simples tipos 1 e 2 (HSV-1 e HSV-2), vírus varicela-zóster, vírus Epstein-Barr, citomegalovirus e os herpesvirus humanos tipos 6,7 e $8^{1}$. Devido à sua freqüência em nosso meio, ênfase especial tem sido dispensada aos tipos HSV-1 e HSV-2. A discriminação clinicolaboratorial entre as infecções causadas por

Departamento de Ginecologia e Obstetrícia, da Faculdade de Medicina de Ribeirão Preto

Hospital das Clínicas da Faculdade de Medicina de Ribeirão Preto - Universidade de São Paulo

Correspondência:

Geraldo Duarte

Departamento de Ginecologia e Obstetrícia

Faculdade de Medicina de Ribeirão Preto - Universidade de São Paulo.

Av. Bandeirantes, 3900

14049-900 - Ribeirão Preto - SP

e-mail: gduarte@fmrp.usp.br esses dois virus ainda é limitada por sérias dificuldades, visto que suas manifestações clínicas se assemelham e as provas sorológicas apresentam elevadas taxas de reações cruzadas ${ }^{2}$. Apesar de o HSV-1 ser mais freqüentemente causador de lesões orolabiais, este virus está presente em até $10 \%$ das lesões herpéticas genitais. Por sua vez, o HSV-2 é responsável por até $90 \%$ das lesões genitais e pode estar presente em até $10 \%$ das lesões orolabiais ${ }^{3}$.

Em estudo epidemiológico no qual se avaliou a soropositividade do HSV-2 em gestantes de diferentes classes sociais, Weinberg et al. ${ }^{4}$ encontraram $31 \%$ de exames positivos entre gestantes de elevado nível sócio-econômico e $46 \%$ naquelas de baixo poder aquisitivo. No entanto, esta diferença não foi significante. Por sua vez, Santos et al. ${ }^{5}$ avaliaram a presença de anticorpos contra o HSV-2 entre pacientes de alto risco para doenças sexualmente transmissiveis na cidade do Rio de Janeiro e observaram $53,8 \%$ de soropositividade para este vírus.

Tanto a primo-infecção pelo HSV-1 como pelo HSV-2 podem causar quadro clínico característico 
da infecção herpética ou serem assintomáticas, com desenvolvimento posterior de períodos de latência e episódios de recorrência ${ }^{6}$. A apresentação clínica da infecção herpética genital em gestantes assemelha-se àquela encontrada em não gestantes. Segundo Brown et al. ${ }^{7}$, o risco de se adquirir infecção herpética durante a gestação é de $2 \%$ na população de gestantes normais por eles avaliada.

Como as infecções genitais são freqüentemente causadas pelo HSV-2, é lógica e previsivel a conclusão de que este tipo viral seja o principal agente causador da infecção herpética perinatal ${ }^{8}$. Este é um dos motivos da importância de se diferenciar a infecção herpética causada pelo HSV-1 daquela causada pelo HSV-2.

Acredita-se que a taxa de transmissão da infecção por HSV-2 aos recém-nascidos seja de 40 a $50 \%$ nas gestantes com infecção primária e de cerca de 3 a $5 \%$ naquelas com infecção recorrente ${ }^{9}$. Na infecção primária, os efeitos histotóxicos para o feto são mais acentuados ${ }^{10}$. A idade gestacional em que ocorre a infecção herpética também é outro fator importante. Se a infecção ocorrer durante a organogênese, freqüentemente provoca prejuízos ao embrião o que é evidenciado por altas taxas de abortos espontâneos, defeitos congênitos e natimortos ${ }^{11}$. Felizmente, defeitos congênitos graves são raros, destacando-se, dentre outros: microcefalia, calcificações intracranianas, coriorretinite e microftalmia $^{12}$. Não está claro se existe relação direta de causa-efeito entre a infecção herpética e a freqüência do trabalho de parto pré-termo, apesar das elevadas taxas de prematuridade (40-50\%) em gestantes portadoras de HSV-2 ${ }^{13}$. Entretanto, não existem dúvidas que os casos de herpes neonatal decorrentes de contaminação no canal de parto respondem pelo maior número das complicações desta infecção entre recém-nascidos ${ }^{14}$.

A conduta obstétrica em face da gestante com infecção herpética vem sofrendo várias mudanças. Atualmente, recomenda-se cesárea para gestantes em trabalho de parto com lesões clínicas evidentes e/ou aquelas que tiveram ruptura das membranas amnióticas por tempo inferior a quatro horas ${ }^{15}$.

Apesar dos avanços tecnológicos, ainda há dificuldades para o diagnóstico laboratorial preciso e rápido com um teste que possibilite diferenciar os dois tipos de virus herpes simples. Várias técnicas têm sido descritas, dentre elas a cultura viral, a citologia, microscopia eletrônica, reação de fixação de complemento, enzyme-linked immunosorbent assay (ELISA), Western blot e reação em cadeia da polimerase (PCR). A cultura viral, apesar de diagnosticar e diferenciar os tipos virais de HSV, retardaria o diagnóstico pela lentidão do crescimento viral (em torno de 10 dias) e apresenta custo elevado, necessitando de técnicos treinados e equipamentos apropriados ${ }^{2}$. Por sua vez, a citologia não detecta a presença viral, identificando apenas as alterações celulares provocadas por esse virus, e sua sensibilidade não ultrapassa $60 \%{ }^{16}$. A microscopia eletrônica é utilizada no di- agnóstico das lesões herpéticas ativas, mas tanto a sensibilidade como a especificidade são baixas, além de apresentar alto custo ${ }^{16}$. A fixação de complemento, a microneutralização e ELISA são testes sorológicos que diagnosticam a infecção herpética através da pesquisa de anticorpos anti-HSV. Estas técnicas apresentam alta sensibilidade e avaliam infecção pregressa pelo HSV, embora não discriminem adequadamente os tipos virais ${ }^{2}$. O Western blot é uma técnica específica para o diagnóstico da infecção causada pelo HSV-2, utilizado como teste confirmatório. Esse teste identifica anticorpos contra a gG-2, uma glicoproteína do envelope viral, específica deste ${ }^{17}$. Por sua vez, a técnica de PCR é altamente específica para o diagnóstico das infecções herpéticas, mas apresenta custo elevado para a nossa realidade ${ }^{18}$.

Em resumo, um dos objetivos deste estudo foi avaliar a taxa de soropositividade contra os vírus HSV-1 e HSV-2 entre parturientes, uma vez que não existem avaliações dessa natureza em nosso meio. O segundo objetivo foi padronizar técnicas de ELISA e Western blot que possibilitem a diferenciação entre o HSV-1 e o HSV-2.

\section{Pacientes e Métodos}

Neste estudo foram analisadas 1.500 amostras sangüíneas de parturientes atendidas no Centro Obstétrico do Departamento de Ginecologia e Obstetrícia do Hospital das Clínicas da Faculdade de Medicina de Ribeirão Preto - Universidade de São Paulo (HCFMRP-USP), durante o período de 1 de janeiro a 31 de outubro de 1996. As parturientes foram submetidas à coleta de amostras sangüineas para exames básicos da rotina laboratorial de pré-parto (tipagem sangüinea, fator RH, sorologias para sífilis, doença de Chagas, hepatite B e virus da imunodeficiência adquirida). Para este trabalho, utilizou-se uma alíquota deste soro, que foi armazenada a $-20^{\circ} \mathrm{C}$. O estudo foi realizado de forma anônima, com aprovação da Comissão de Ética Médica desta instituição.

O Centro de Processamento de Dados do Estado de São Paulo (PRODESP) forneceu os dados referentes às pacientes atendidas neste periodo, considerando a idade, a cor da pele, a procedência, a profissão e a escolaridade.

\section{Métodos Laboratoriais}

Para o diagnóstico das infecções herpéticas foram padronizadas duas técnicas. A primeira, considerada como triagem, baseou-se em técnica imunoenzimática (ELISA). A segunda técnica padronizada foi o Western blot, utilizada como exame confirmatório para identificação de anticorpos contra o HSV-2 em 250 amostras escolhidas de forma aleatória entre aquelas que se mostraram positivas pelo ELISA.

Para padronização do teste de ELISA as cul- 
turas de células VERO (células de rim de macaco verde africano; ATCC No. CCL-56) foram infectadas com virus HSV-1 ou com HSV-2. Na presença do efeito citopático, submeteram-se as monocamadas celulares à ação da tripsina, ressuspendendo-as em seguida no próprio meio de cultura (MEM). Esta suspensão foi transferida para tubos cônicos, centrifugando-os a 3000 rotações por minuto (rpm) durante 15 minutos, a $4^{\circ} \mathrm{C}$ (Beckman GPR Centrifuge, Palo Alto, CA, USA). O pellet celular foi lavado por 2 vezes com PBS (Dulbecco's phosfatebuffered saline - Gibco BRL, Life Technologies Inc., Grand Island, NY, USA) estéril gelado, centrifugando-o nas mesmas condições anteriores. $\mathrm{O}$ pellet foi ressuspenso com solução de lise para ELISA (glicina 0,01 M, Tris 0,038 M, Triton-X 100 $1 \%$, água deionizada qsp, em $\mathrm{pH} 9,0$ ), na proporção de 1:10 (p/v). A solução foi submetida a ondas de ultra-som em gelo por 30 segundos a 50 watts e centrifugada a $3000 \mathrm{rpm}$, sendo transferida para tubos de microcentrífuga e armazenada a $-70^{\circ} \mathrm{C}$. O controle negativo foi obtido por processo semelhante, utilizando-se células VERO não infectadas.

As placas para ELISA foram sensibilizadas com $100 \mu 1$ de antígenos do HSV-1, do HSV-2 e do controle negativo, diluídos em PBS-T (PBS associado a Tween-20: Quimiobrás Indústrias Químicas S.A., Rio de Janeiro, RJ, Brasil) na concentração de $1: 200$, sendo incubadas por 1 hora a $37^{\circ} \mathrm{C}$. A seguir iniciou-se o bloqueio com acréscimo de solução de albumina sérica bovina (BSA) a 10\%, diluída em PBS-T por 2 horas a $4^{\circ} \mathrm{C}$. Posteriormente, foram adicionados $100 \mu 1$ dos soros das pacientes (previamente incubados a $56^{\circ} \mathrm{C}$ por 30 minutos) por unidade de reação da placa, na concentração de $1: 100$, incubando por 1 hora a $37^{\circ} \mathrm{C}$. Para controle dos testes foram utilizados soros positivos obtidos de pacientes com infecção herpética comprovada clinicamente e soro controle negativo gentilmente cedido pelo Instituto Adolfo Lutz de São Paulo (Brasil). Em seqüência, adicionava-se $100 \mu 1$ de antiIgG humana conjugada à peroxidase (Sigma Chemical Co., St. Louis, MO, USA), na concentração de 1:1000 diluída em PBS-T, e incubou-se por 1 hora a $37^{\circ} \mathrm{C}$. Foi adicionado o substrato da enzima peroxidase, o OPD (O-phenylenediamine dihydrocloride, Sigma), diluído conforme orientações do fornecedor. Depositava-se $100 \mu 1$ do substrato em cada unidade de reação da placa e incubou-se a $37^{\circ} \mathrm{C}$ por 20 a 30 minutos. A densidade óptica do produto de cada reação foi lida no densitômetro óptico da Molecular Devices Corporation (Sunnyvale, CA, USA), em comprimento de onda de $490 \mathrm{~nm}$. Ressalta-se que entre cada passo deste procedimento, eram lavadas as placas por 3 vezes com PBS-T. Cada amostra foi testada em duplicata tanto para HSV-1 como para HSV-2.

Com base na absorbância foram calculadas a média e o desvio padrão das amostras, sendo consideradas positivas aquelas que apresentaram valor de absorvância acima de dois desvios-padrão da média dos valores observados para os controles negativos. O ponto de corte era calculado diaria- mente por meio da média dos exames de pacientes sabidamente negativos, com posterior cálculo do desvio-padrão. Desta maneira, assegurou-se que o erro em considerar uma amostra falso-positiva foi de $0,005 \%$.

Para avaliar a validade da técnica de ELISA para identificação de anticorpos contra os HSV, foram usadas 20 amostras sangüíneas de pacientes com diagnóstico pregresso dessa infecção. Desta forma foi obtida uma sensibilidade de $100 \%$ e especificidade de $75 \%$.

Dentre as amostras que apresentaram IgG anti-HSV detectada por ELISA, 250 foram testados pela técnica de Western blot, reação que possibilita identificar o HSV-2 por meio da presença de anticorpos contra uma glicoproteína exclusiva do envelope viral.

Os passos iniciais desta técnica assemelham-se aos utilizados para o preparo do antígeno na técnica de ELISA, sendo as culturas de células VERO infectadas com o HSV-2. A seguir, foram coletadas as células lavando-as com PBS-T, utilizando centrifugação. A seguir, adicionou-se o tampão de lise e submeteu-se esta solução a ondas de ultra-som por 30 segundos a 50 watts. Posteriormente, realizou-se eletroforese para separação das proteínas do HSV-2, utilizando-se o antígeno diluído em tampão de lise. Para a eletroforese, utilizou-se gel de poliacrilamida, nas concentrações de 4 e 8\% (National Diagnostics, New Jersey, NJ, USA), em equipamento Mini Protean II (Bio-Rad Laboratories, Hercules, CA, USA), a 100 volts durante duas horas. Em seguida, as proteinas foram transferidas para um papel de nitrocelulose, utilizando voltagem constante de 100 volts por duas horas. A eficiência da transferência das proteínas do HSV-2 para o papel de nitrocelulose foi verificada pela coloração com Ponceau-S a 5\%. O papel de nitrocelulose foi cortado em tiras as quais foram bloqueadas com BSA a 3\%, por 2 horas, à temperatura ambiente e sob agitação constante. A seguir, as tiras de papel de nitrocelulose foram lavadas com PBS, e foram adicionadas as amostras séricas HSV-positivas pelo teste de ELISA, na concentração de 1:50. Incubou-se por toda a noite, à temperatura ambiente e sob agitação constante. Procedeu-se a duas lavagens com PBS-T e, na seqüência, adicionou-se a imunoglobulina anti-IgG humana conjugada à enzima fosfatase alcalina, na concentração de 1:1000, diluída em PBS, incubando-se por uma hora, em temperatura ambiente, sob agitação constante. Em seguida, estas tiras foram submetidas a novas lavagens com PBS-T. A presença de anticorpos anti HSV-2 foi revelada com o uso do "Western Blue ${ }^{R}$ Stabilized Substrate for Alkaline Phosphatase" (Promega), tendo como reveladores o BCIP (5-bromo-4-chloro 3-indolyl phosphate, $p$ toluidine salt) e o NBT (nitro blue tetrazolium).

\section{Resultados}

Com base nos dados da PRODESP, inferiu-se 
que a população deste estudo foi constituída de mulheres com idades variando entre 13 a 49 anos, encontrando-se a maioria (32\%) na faixa etária de 20 a 25 anos. Em relação à cor da pele, $66,8 \%$ eram brancas, $22,2 \%$ mulatas, $10,7 \%$ negras e $0,3 \%$ amarelas. A maioria das pacientes eram provenientes de Ribeirão Preto, donas de casa e com grau de escolaridade caracterizado como do ensino fundamental.

Das 1500 amostras séricas analisadas pelo método de ELISA para os HSV (HSV-1 e HSV-2), foram obtidas 1358 amostras positivas para ambos os virus, 27 amostras positivas somente para o HSV-2 e 32 amostras positivas somente para o HSV-1. As 83 amostras restantes foram negativas para ambos os vírus.

Considerando-se como positivas aquelas amostras que apresentaram positividade para pelo menos um dos virus, o total de amostras positivas para HSV foi de 1417. Estes dados indicam prevalência de anticorpos contra os HSV nas parturientes do HC FMRP-USP de 94,5\%. As amostras que apresentavam positividade para o HSV-2 somaram 1385, significando soropositividade para o HSV-2 de 92,3\% (Tabela 1).

Tabela 1 - Distribuição numérica dos resultados de ELISA para HSV-1 e HSV-2 em 1500 parturientes atendidas no HCFMRP-USP.

\begin{tabular}{|c|c|c|c|c|c|c|c|}
\hline & \multicolumn{7}{|c|}{ Amostras séricas testadas para o $\mathrm{HSV}-2$} \\
\hline & & \multicolumn{2}{|c|}{ Positivo } & \multicolumn{2}{|c|}{ Negativo } & \multicolumn{2}{|c|}{ Total } \\
\hline & & $\mathbf{n}$ & $\%$ & $\mathrm{n}$ & $\%$ & $\mathrm{n}$ & $\%$ \\
\hline \multicolumn{2}{|l|}{ Amostras séricas } & 1358 & 90,6 & 32 & 2,1 & 1390 & 92,7 \\
\hline testadas para & Positivo & 27 & 1,8 & 83 & 5,5 & 110 & 7,3 \\
\hline \multirow[t]{2}{*}{ HSV-1 } & Negativo & 1385 & 92,4 & 115 & 7,6 & 1500 & 100 \\
\hline & Total & & & & & & \\
\hline
\end{tabular}

Para discriminar anticorpos específicos contra o HSV-2, o Western blot foi realizado em 250 das amostras positivas por ELISA. Destas, 88 foram positivas pela técnica confirmatória, representando positividade de $35,2 \%$. Corrigindo-se este número para o número total de amostras dessa casuística (1500), deduz-se que a soroprevalência do HSV-2 nessa população foi de 31,9\%.

\section{Discussão}

As infecções causadas pelos HSV sempre foram motivo de preocupação e questionamentos entre os pesquisadores desse tema. Cerca de 300.000 novos casos de infecções genitais pelo HSV-2 são diagnosticados anualmente em mulheres norte-americanas ${ }^{19}$. Como a maioria dos casos são observados entre mulheres na fase reprodutiva, pode-se predizer que há um elevado número de gestantes afetadas, sendo esta uma preocupação adicional para os tocoginecologistas. Em relação à transmissão vertical, o HSV-2 é o mais importante, quer pela sua apresentação clí- nica (trato genital inferior) ou por suas características de infectividade, número de episódios de repetição e duração da doença ${ }^{20}$.

Em face do elevado número de casos assintomáticos para se avaliar a freqüência da infecção pelos HSV, torna-se imprescindivel o uso de técnicas laboratoriais que permitem detecção dos anticorpos contra esses vírus. Dentre as técnicas sorológicas utilizadas para determinar a soroprevalência de anticorpos anti-HSV, a preferência dos pesquisadores baseia-se nas técnicas de ELISA e Western blot ${ }^{21}$.

Em 1983, Coleman et al. ${ }^{22}$ desenvolveram um teste de ELISA específico para os tipos virais, utilizando a glicoproteina gB-1 para o HSV-1 e polipeptídeos purificados para o HSV-2. Em trabalhos de avaliação destas técnicas, alguns autores revelam sensibilidade e especificidade que chegam a 95 a $100 \%{ }^{23}$. Entretanto, outros relatam que a sensibilidade é elevada apenas para o diagnóstico da infecção herpética aguda ${ }^{21}$ e que as elevadas taxas de reatividade cruzada entre o HSV-1 e o HSV-2 fazem com que estes testes sejam incapazes de discriminar os tipos virais, servindo apenas para triagem da infecção viral ${ }^{24}$. Além destas limitações há o custo dos kits de ELISA, mas existe a possibilidade de se produzir em nossos laboratórios um teste com especificações que ofereçam uma alternativa com custo reduzido.

$\mathrm{Na}$ confecção do teste de ELISA, proposto neste trabalho, sensibilizava-se placas com dois antígenos, o HSV-1 e o HSV-2, separadamente, objetivando-se conhecer a reatividade específica de cada um dos vírus. Visando o aumento da especificidade do teste foram utlizados anticorpos monoclonais contra o complexo antígeno-anticorpo formado nas paredes das placas. Entretanto, mesmo com este recurso adicional o teste não possibilitou a discriminação dos tipos virais.

Se por um lado o teste aqui estudado não conseguiu discriminar os tipos virais completamente, refletindo-se na baixa especificidade $(75 \%)$, por outro lado pode ser considerado como triador das infecções prévias por HSV (100\% de sensibilidade).

Analisando todos os resultados obtidos com o teste ELISA obteve-se uma soroprevalência contra ambos os HSV de 94,5\%, considerando a positividade contra ambos os virus ou isoladamente ou em associação. Após uma avaliação geral da presença dos anticorpos contra os HSV, na população estudada, passou-se à avaliação da prevalência de anticorpos contra o HSV-2 entre as parturientes, utilizando a técnica de Western blot. Outros trabalhos já haviam demonstrado ser esta técnica de alta especificidade, apresentando melhores resultados para discriminação viral ${ }^{21,24}$.

As amostras testadas pelo Western blot foram selecionadas ao acaso, dentre as amostras positivas pelo ELISA contra o HSV-2, evitando qualquer risco de testar somente as amostras que apresentavam altos títulos de anticorpos contra o HSV-2. Os pesquisadores responsáveis pela execução do Western blot e pela seleção das amostras não ti- 
nham conhecimento da titulação obtida com o teste de ELISA. O desconhecimento dos dados clínicos também evitou resultados tendenciosos, aumentando a fidelidade do teste.

O método de Western blot, apesar de ter custo mais elevado e necessitar de técnicas mais apuradas, mostrou-se eficiente na discriminação dos tipos virais. A presença de anticorpos contra a glicoproteina gG-2 foi suficiente para caracterizar soros como positivos para HSV-2, observando-se uma positividade de $31,2 \%$ da população geral.

Para avaliação fidedigna dos dados obtidos, é válido lembrar que a soroprevalência dos HSV sofre influências de vários fatores, dentre eles, a idade, a raça, o local de residência e as condições socioeconômicas dos participantes. Sendo assim, torna-se necessário informar em que população os resultados foram obtidos.

Em relação às gestantes infectadas pelo HSV2 , acredita-se que $80 \%$ das pacientes estejam na faixa etária de 15 a 34 anos de idade ${ }^{14}$. As gestantes deste trabalho concentraram-se em sua maioria na faixa etária dos 20-25 anos, com uma prevalência de $31,2 \%$ para o HSV-2, confirmando a precocidade e a alta incidência desta infecção em nosso meio.

A raça é considerada fator determinante na prevalência do HSV-2, havendo predomínio de anticorpos contra esse vírus em mulheres negras. Quando se avalia a prevalência do HSV em gestantes, observa-se que a infecção por HSV-1 ocorre em torno de $100 \%$ das mulheres negras africanas ou caribenhas e em $60-80 \%$ das mulheres brancas da Ásia e Inglaterra, ao passo que a infecção por HSV-2 ocorre em 35\% das mulheres negras e $10 \%$ das brancas ${ }^{25}$. No presente estudo, encontrou-se maior predominio de anticorpos contra o HSV-2 nas mulheres brancas. Este fato pode ser explicado pela falta de critérios para se considerar uma paciente negra ou branca.

Outro quesito avaliado na presente casuística foi o nivel socioeconômico das parturientes. A população estudada caracterizou-se por apresentar baixo poder aquisitivo, sendo epidemiologicamente mais predisposta à infecção pelos HSV-2 ${ }^{26}$. Em 1993, Weinberg et al. ${ }^{4}$ avaliaram a freqüência de soropositividade contra os HSV em parturientes de São Paulo. Considerando populações de alto e baixo nível socioeconômico, a positividade foi detectada em $86 \%$ e $92 \%$ dos casos, respectivamente. Analisando apenas anticorpos contra o HSV-2, esses autores descreveram prevalência de $31 \%$ para o primeiro e $42 \%$ para o segundo grupo. Os resultados obtidos entre as gestantes de baixo poder aquisitivo são praticamente semelhantes àqueles encontrados no presente trabalho. Para Santos et al. ${ }^{5}$ a soropositividade contra o HSV-2 foi de 53,8\% em pacientes da cidade do Rio de Janeiro. Este estudo incluiu homens e mulheres em diferentes grupos, dentre outros, homossexuais, doadores de sangue e prostitutas. Talvez por ser essa população de maior risco para a infecção pelo HSV-2, a prevalência encontrada por esses autores seja mais elevada que aquela encontrada nesta casuística.
Apesar da alta prevalência da infecção por HSV entre nós, a doença clínica não tem sido descrito com a mesma freqüência. Dois fatores justificam esta assertiva, o primeiro diz respeito à incapacidade de se fazer diagnóstico correto, sendo a notificação efetuada apenas em casos de extrema gravidade. O segundo se refere ao fato de que a maioria da população tem imunidade para o HSV-1, o que foi comprovado neste trabalho. Assim, a imunidade materna contra o HSV-1 poderia proteger o feto dos efeitos deletérios da infecção por HSV-2 durante a gestação ${ }^{27}$. Episódios sintomáticos ou assintomáticos de infecção pelos HSV, que ocorreram em mulheres com infecção prévia pelo HSV-1, podem cursar com escassas ou mesmo nenhuma manifestação tanto para a mãe como para o feto, porque há uma redução da replicação viral local causada pela presença de anticorpos IgG para HSV-1. Esses anticorpos podem neutralizar o HSV-2 ou participar da lise de células infectadas com HSV-2, por mecanismos de citotoxidade anticorpo-dependente ${ }^{28}$. A imunidade cruzada contra a infecção do HSV-1 preexistente também pode reduzir o risco da infecção fetal, evitando a viremia materna ou a infecção ascendente através de membranas intactas ${ }^{29}$.

Com os dados deste estudo, conclui-se que existe elevada prevalência da infecção por HSV na população estudada, o que exige maior atenção quanto à avaliação das gestantes, visto que percentual significativo desta infecção é devido ao HSV-2. A combinação do ELISA e do Western blot na triagem sorológica para o HSV-2 parece ser lógica. A técnica de ELISA não discrimina os tipos virais. Entretanto, por ser um teste rápido, simples e de baixo custo, deve ser utilizado como triador nos casos de infecção herpética. O Western blot é uma técnica de elevada especificidade e custo mais elevado, necessitando de maiores cuidados técnicos. Entretanto, após a sua padronização e se for realizada para um grande número de pacientes, tende a ser reduzido seu custo operacional.

\section{SUMMARY}

Purpose: to evaluate the seroprevalence of infection caused by HSV-2 among pregnant women delivering at the University Hospital, Faculty of Medicine of Ribeirão Preto (UHFMRP-USP) and to standardize laboratory techniques to be used for this purpose.

Methods: a total of 1500 blood samples from pregnant women seen at the Obstetric Center of the Department of Gynecology and Obstetrics, UHFMRP-USP, between January 1st and October 31st, 1996, were evaluated. To determine the real prevalence of HSV-2 infection, the ELISA technique was standardized but, during its initial use, it was found to be not sufficiently specific to discriminate between the two viral types (75\%). Thus, it became necessary to use a more specific technique and the method standardized for this purpose was Western blot, which can detect the specific HSV-2 viral protein. Results: the seroprevalence of herpes infection induced by the two viral types (HSV-1 and HSV-2) was $94.5 \%$ when ELISA 
was used. With the use of Western blot, a $32 \%$ seroprevalence of HSV-2 infection was detected in the studied population, whether symptomatic or asymptomatic.

Conclusion: a high prevalence of carrier status for HSV-2 and HSV-1 infection was detected, as shown by the high rate of positivity for antibodies against this virus. ELISA did not show sufficient specificity to discriminate between $\mathrm{HSV}-2$ and $H S V-1$ antibodies.

KEY-WORDS: Herpes simplex virus. HSV seroprevalence birth deffects.

\section{Referências}

1. Murphy FA. Virus taxonomy. In: Fields BN, Knipe DM, Howley PM, editors. Fundamental virology. $3^{\text {rd }}$ ed. Philadelphia: Lippincott-Raven; 1995. p.15-57.

2. Mertz GJ. Herpes simplex virus. In: Galasso RJ, Whitley RJ, Merigan TC, editors. Practical diagnosis of viral infections. $2^{\text {nd }}$ ed. New York: Raven; 1993. p.121-30.

3. Lycke E. The pathogenesis of the genital herpes simplex virus infection. Scand J Infect Dis Suppl 1991; 80:714.

4. Weinberg A, Canto CL, Pannuti CS, Kwang WN, Garcia SA, Zugaib M. Herpes simplex virus type 2 infection in pregnancy: asymptomatic viral excretion at delivery and seroepidemiologic survey of two socioeconomically distinct populations in São Paulo, Brazil. Rev Inst Med Trop São Paulo 1993; 35:285-90.

5. Santos OLR, Silva AG, Gonçalves AS, Pereira Júnior AC. Herpes simples genital, uma doença sexualmente transmissivel. Folha Méd 1995; 110:77-98.

6. Corey L. The current trend in genital herpes. Progress in prevention. Sex Transm Dis 1994; 21Suppl:S38-44.

7. Brown ZA, Selke S, Zeh J, et al. The acquisition of herpes simplex virus during pregnancy. N Engl J Med 1997; 337:509-15.

8. Malm G, Berg U, Forsgren M. Neonatal herpes simplex: clinical findings and outcome in relation to type of maternal infection. Acta Paediatr 1995; 84:256-60.

9. Kulhanjian JA, Soroush V, Au DS, et al. Identification of women at unsuspected risk of primary infection with herpes simplex virus type 2 during pregnancy. N Engl J Med 1992; 326:916-20.

10.Brown ZA, Vontver LA, Benedetti J, et al. Genital herpes in pregnancy: risk factors associated with recurrences and asymptomatic viral shedding. Am J Obstet Gynecol 1985; 153:24-30.

11.Sison AV, Sever JL. Infecções virais. In: David C, Sanford JP, Tyrrell DA, Weller TH, Wolff SM, editores. Infecções Obstétricas e Perinatais. $1^{\mathrm{a}}$ ed. Porto Alegre: Artes Médicas; 1995. p.173-225.

12.Florman AL, Gershon AA, Blackett PR, Nahmias AJ. Intrauterine infection with herpes simplex virus. Resultant congenital malformations. JAMA 1973; 225:129-32.

13.Brown ZA, Benedetti J, Selke S, Ashley R, Watts DH, Corey L. Asymptomatic maternal shedding of herpes simplex virus at the onset of labor: relationship to preterm labor. Obstet Gynecol 1996; 87:483-8.
14.Boucher FD, Yasukawa LL, Bronzan RN, Hensleigh PA, Arvin AM, Prober CG. A prospective evaluation of primary genital herpes simplex virus type 2 infections acquired during pregnancy. Pediatr Infect Dis J 1990; 9:499-504

15.Gibbs RS, Amstey MS, Lezotte DC. Role of cesarean delivery in preventing neonatal herpes virus infection. JAMA 1993; 270:94-5.

16.Ashley RL, Dalessio J, Dragavon J, et al. Underestimation of HSV-2 seroprevalence in a highrisk population by microneutralization assay. Sex Transm Dis 1993; 20:230-5.

17.Ashley RL, Militoni J, Lee F, Nahmias A, Corey L. Comparison of Western blot (immunoblot) and glycoprotein G-specific immunodot enzyme assay for detecting antibodies to herpes simplex virus types 1 and 2 human sera. J Clin Microbiol 1988; 26:662-7.

18.Baron JM, Rübben A, Grussendorf-Conen EI. Evaluation of a new general primer pair for rapid detection and differentiation of HSV-1, HSV-2, and VZV by polymerase chain reaction. J Med Virol 1996; 49:279-82.

19. Naeye RL. Placenta e membranas. In: Charles D, Sanford JP, Tyrrell DA, Weller TH, Wolff SM, editores. Infecções Obstétricas e Perinatais. $1^{\text {a }}$ ed. Porto Alegre: Artes Médicas; 1995. p. 398-431.

20.Sucato G, Wald A, Wakabayashi E, Vieira J, Corey L. Evidence of latency and reactivation of both herpes simplex virus (HSV)-1 and HSV-2 in the genital region. $\mathrm{J}$ Infect Dis 1998; 177:1069-72.

21.Field PR, Ho DW, Irving WL, Isaacs D, Cunningham AL. The reliability of serological tests for the diagnosis of genital herpes: a critique. Pathology 1993; 25:1759.

22. Coleman RM, Pereira L, Bailey PD, Dondero D, Wickliffe C, Nahmias AJ. Determination of herpes simplex virus type-specific antibodies by enzymelinked immunosorbent assay. J Clin Microbiol 1983; 18:287-91.

23.Verano L, Michalski FJ. Herpes simplex virus antigen direct detection in standard virus transport medium by Du Pont Herpchek enzyme-linked immunosorbent assay. J Clin Microbiol 1990; 28:2555-8.

24.Ashley R, Cent A, Maggs V, Nahmias A, Corey L. Inability of enzyme immunoassays to discriminate between infections with herpes simplex virus types 1 and 2. Ann Intern Med 1991; 115:520-6.

25.Ades AE, Peckham CS, Dale GE, Best JM, Jeansson S. Prevalence of antibodies to herpes simplex virus types 1 and 2 in pregnant women, and estimated rates of infection. J Epidemiol Community Health 1989; 43:53-60.

26.Stavraky KM, Rawls WE, Chiavetta J, Donner AP, Wanklin JM. Sexual and socioeconomic factors affecting the risk of past infections with herpes simplex virus type 2. Am J Epidemiol 1983; 118:109-21.

27.Taina $E$, Hänninen $P$, Grönroos M. Viral infections in pregnancy. Acta Obstet Gynecol Scand 1985; 64:16773.

28.Freij BJ, Sever JL. Herpesvirus infections in pregnancy: risks to embryo, fetus, and neonate. Clin Perinatol $1988 ; 15: 203-31$.

29.Hutto C, Arvin A, Jacobs R, et al. Intrauterine herpes simplex virus infections. J Pediatr 1987; 110:97-101. 